\title{
Ketersediaan dan Pola Distribusi Garam Beriodium di Kabupaten Jepara
}

\author{
Wiwid Widiyatni ${ }^{1}$, Hertanto Wahyu Subagio ${ }^{2}$, Suhartono ${ }^{3}$
}

\begin{abstract}
Background: universal salt iodization (USI) was the main program to overcome iodine deficiency disorders (IDD) in Indonesia. The uneven availability and distribution of iodized salt according to Indonesian National Standard (SNI) became a problem to reach USI in some part of Indonesia, including in Jepara. Jepara was one of the city in Central Java province which produced salt. Unfortunately, most of those salt was sold outside Jepara area while iodized salt needed by Jepara community was supplied from area outside Jepara.

Objective: the aim of this research was to analyze the availability and distribution pattern of iodized salt in Jepara regency.

Methods: qualitative method was used in this research. The main informants consist of five member from IDD prevention team and eleven salt producers. Data collected through observation, in-depth interview and documents review. Data was analyzed using content analysis method.

Results: 76 iodized salt brands were circulated in jepara, $75 \%$ of them have iodine contain under 30 ppm. The circulated unstandardized salts were caused by the lack of law enforcement from Jepara Government. The difference in distribution pattern also caused the difference in the availability of iodized salt in some regions in Jepara. There were 8-14 salt brands and krosok salt in every region in Jepara.

Conclusion: Most of iodized salt circulated in Jepara contain iodine less than 30 ppm. There were 8-14 salt brands and krosok salt in every region in Jepara.
\end{abstract}

Keywords: availability, distribution pattern, iodized salt, Jepara

\section{ABSTRAK}

Latar belakang : Konsumsi garam beriodium oleh masyarakat atau Universal Salt Iodization (USI) merupakan program utama penanggulangan GAKI di Indonesia. Ketersediaan dan distribusi garam beriodium sesuai SNI yang belum merata menjadi kendala tercapainya USI di beberapa wilayah Indonesia termasuk Jepara. Jepara merupakan salah satu daerah penghasil garam di Jawa Tengah. Sebagian besar garam dijual keluar daerah sedangkan seluruh kebutuhan garam beriodium disuplai dari luar daerah. Penelitian bertujuan untuk menganalisis ketersediaan, pola distribusi dan tingkat konsumsi garam beriodium di Kabupaten Jepara.

Metode : Metode kualitatif digunakan dalam penelitian ini. Informan utama terdiri dari 5 orang anggota tim penanggulangan GAKI dan 11 orang pelaku garam. Informan triangulasi terdiri dari 30 orang ibu hamil di wilayah Pakis Aji. Pengumpulan data melalui observasi, wawancara mendalam, Focus Group Discusion dan telaah dokumen. Analisis data menggunakan content analysis.

Hasil : Terdapat 76 merk garam beriodium yang beredar di Jepara, $75 \%$ mengandung iodium < 30 ppm. Tingginya peredaran garam ini disebabkan oleh lemahnya law enforcement di Jepara. Pola distribusi yang berbeda mengakibatkan ketersediaan garam beriodium di setiap wilayah juga berbeda. Sebagian besar responden telah mengonsumsi garam beriodium. Persepsi responden gondok merupakan dampak utama GAKI. Garam beriodium tersedia di pasar atau warung dengan harga terjangkau, rasa dan kualitas garam menjadi kendala dalam mengonsumsi garam beriodium sesuai SNI setiap hari.

Simpulan : Sebagian besar (75\%) garam beriodium yang beredar mengandung iodium < 30 ppm. Terdapat 8-14 merk garam serta penjual garam krosok curah dan kemasan di setiap wilayah. Sebagian besar responden telah mengonsumsi garam beriodium.

Kata Kunci : ketersediaan, pola distribusi, konsumsi, garam beriodium, Jepara

\section{PENDAHULUAN}

Gangguan Akibat Kekurangan Iodium (GAKI) merupakan rangkaian akibat kekurangan iodium pada tumbuh kembang manusia yang memiliki spektrum luas seperti abortus, lahir mati, hipotiroid neonatal, kretin, ganguan pertumbuhan dan perkembangan serta gondok. Dampak GAKI sangat serius karena

\footnotetext{
${ }^{1}$ Dinas Kesehatan Kabupaten Jepara

${ }^{2}$ Fakultas Kedokteran Universitas Diponegoro

${ }^{3}$ Fakultas Kesehatan Masyarakat Universitas Diponegoro
}

mempengaruhi kelangsungan hidup dan kualitas sumber daya manusia. ${ }^{1}$

Sejak tahun 2009, penanggulangan GAKI bertumpu pada konsumsi garam beriodium oleh masyarakat atau USI (Universal Salt Iodization), yaitu lebih dari $90 \%$ rumah tangga mengonsumsi garam yang difortifikasi $\mathrm{KIO}_{3}$ sebesar $30-80$ ppm. $^{2}$ Survei konsumsi garam beriodium oleh Badan Pusat Statistik (BPS) tahun 1996 hingga 2003 menunjukkan kenaikan persentase rumah tangga yang mengonsumsi garam beriodium diatas $30 \mathrm{ppm}$ belum begitu berarti, yaitu 
$58,1 \%$ menjadi $73,24 \% .{ }^{3}$ Begitu pula hasil Riskesdas tahun 2007 dan 2013 yaitu sebesar 62,3\% dan 77,1\%. ${ }^{4,5}$

Kontinyuitas ketersediaan garam beriodium sesuai SNI merupakan salah satu masalah belum tercapainya program USI. Hasil uji petik garam beriodium oleh BPOM di 28 propinsi mulai tahun 2006-2010 menunjukkan baru $70,1 \%$ produk memenuhi syarat ketersediaan garam beriodium. Pemantuan garam beriodium oleh BPOM di Jawa Tengah mendapatkan hasil yang jauh berbeda antara produsen kelas menengah dengan produsen kecil. Garam beriodium dari produsen kelas menengah $78,38 \%$ telah memenuhi syarat sedangkan garam beriodium dari produsen kecil hanya $2,7 \%{ }^{6}$

Distribusi garam beriodium sesuai SNI yang belum merata di seluruh Indonesia juga mempengaruhi tingkat pencapaian USI yang terbagi menjadi 3 Regional. Regional 1 merupakan daerah dengan konsumsi garam beriodium 80-98\% meliputi wilayah Sumatera (kecuali Aceh), Kalimantan, Papua, Sulawesi Utara Gorontalo dan Maluku Utara. Regional 2 merupakan daerah dengan konsumsi garam beriodium sekitar 50-70\% meliputi wilayah pulau Jawa dan Sulawesi (kecuali Sulawesi Utara). Regional 3 merupakan daerah dengan konsumsi garam beriodium $<50 \%$ meliputi wilayah Bali, NTB, NTT, Maluku dan Aceh. ${ }^{6}$

Hasil pemeriksaan ekskresi iodium dalam urin (EIU) di Kabupaten Jepara pada tahun 2007 - 2012 mendapatkan beberapa kecamatan termasuk daerah endemis GAKI yaitu Mayong, Batealit dan Pakis Aji. Tingkat konsumsi garam beriodium rumah tangga di Kabupaten Jepara sebesar 79,89\% namun konsumsi garam beriodium cukup (secara kualitatif dengan iodine test) sebesar $60,27 \%$. Jepara merupakan salah satu daerah penghasil garam di wilayah Jawa Tengah. Jumlah petani garam sebanyak 541 orang dengan produksi garam krosok 99,48 ton per hektar per tahun. Sebagian besar garam tersebut dijual keluar Kabupaten Jepara sedangkan kebutuhan garam beriodium dipenuhi oleh produsen garam dari luar wilayah. Hasil pemantauan garam beriodium di pasar mendapatkan sebagian besar garam yang beredar tidak memenuhi syarat serta masih banyaknya pedagang garam krosok. Berdasar uraian tersebut, Bagaimanakah ketersediaan dan pola distribusi garam beriodium di Kabupaten Jepara?

\section{METODE}

Penelitian ini bertujuan untuk menganalisis ketersediaan dan pola distribusi garam beriodium di Kabupaten Jepara. Penelitian menggunakan metode kualitatif. Pengumpulan data melalui observasi, wawancara mendalam (in depth interview) dan telaah dokumen. Pemilihan informan secara purposive sampling sesuai tujuan penelitian. Informan penelitian terdiri dari 5 orang anggota tim penanggulangan GAKI (BAPPEDA, Dinas Kelautan dan Perikanan, Dinas Kesehatan, Dinas Perindustrian dan Perdagangan) serta 11 orang pelaku garam (petani garam, pengepul garam, produsen garam beriodium, pedagang garam dan pedagang garam krosok) di Kabupaten Jepara.

Instrumen yang digunakan dalam penelitian adalah pedoman wawancara, alat perekam suara, alat perekam gambar dan alat tulis. Analisis data menggunakan content analysis dengan tahapan mereduksi data, menyajikan data serta menarik kesimpulan dan verifikasi. Pengujian keabsahan data pada penelitian kualitatif meliputi uji credibility (validitas internal), uji transferability (validitas eksternal), uji dependability (reliabilitas) dan uji confirmability (obyektivitas). ${ }^{7}$

\section{HASIL DAN PEMBAHASAN}

\section{Ketersediaan Garam Beriodium di Kabupaten Jepara}

Sebagian wilayah Kabupaten Jepara merupakan wilayah pantai, 34 dari 195 desa/kelurahan yang ada terletak di pesisir pantai. Letak wilayah ini menjadikan Jepara memiliki potensi tambak garam serta menjadi salah satu daerah penghasil garam di Jawa Tengah. Jumlah petani garam sebanyak 541 orang dengan produksi garam krosok 99,48 ton per hektar per tahun. ${ }^{8}$ Pada tahun 2000, Pemerintah Kabupaten Jepara telah mendorong tumbuhnya industri garam beriodium untuk memenuhi kebutuhan garam beriodium lokal serta meningkatkan harga jual garam para petani dengan mendirikan 5 koperasi garam primer dan 1 koperasi garam sekunder. Berbagai permasalahan membuat koperasi ini tidak berjalan dengan baik bahkan akhirnya semua koperasi berhenti, seperti para anggota yang kurang ulet, banyaknya bantuan koperasi yang teralihkan ke sektor lain serta kalahnya harga garam beriodium di pasar.

Produksi garam krosok yang semakin meningkat dan belum memadainya produsen garam beriodium di Kabupaten Jepara menyebabkan sebagian besar garam krosok ini dijual keluar wilayah sebagai bahan baku industri garam beriodium atau bahan baku industri yang lain. Di sisi lain seluruh kebutuhan garam beriodium disuplai dari luar wilayah yaitu Pati, Demak, Surabaya, Sidoarjo dan Semarang. Garam beriodium tersebut tersedia/mudah didapatkan di pasar atau warung terdekat. Jumlah dan kualitas garam beriodium yang beredar di Kabupaten Jepara dapat dilihat pada tabel 1.

Tabel 1 menunjukkan garam beriodium yang beredar di Kabupaten Jepara sebanyak 76 merk, $75 \%$ (57 merk) mengandung iodium kurang dari $30 \mathrm{ppm}$. Secara kualitatif dengan iodine test 45 merk (59\%) 
mengandung iodium yang cukup (menunjukkan warna biru tua). Hasil observasi peneliti mendapatkan bahwa kandungan iodium diatas $15 \mathrm{ppm}$ telah memberikan warna biru tua pada garam jika diuji dengan iodine test. Produsen garam dari Pati dan Demak sebagian besar memproduksi garam bata dengan kandungan iodium dibawah $30 \mathrm{ppm}$, sedangkan produsen garam nasional di Sidoarjo dan Surabaya memproduksi garam halus dan sebagian besar telah memenuhi SNI. Tabel ini juga menunjukkan adanya 4 jenis garam krosok yang dikemas, meski pada label menyatakan tidak beriodium namun hal ini mengecoh konsumen karena garam yang dikemas identik dengan garam beriodium. Tingkat konsumsi garam beriodium rumah tangga di Kabupaten Jepara sebesar $79,89 \%$. Jika $75 \%$ garam iodium yang beredar mengandung iodium dibawah $30 \mathrm{ppm}$, maka diperkirakan konsumsi garam beriodium yang memenuhi syarat (30 ppm atau lebih) hanya sebesar $19,97 \%$.

Hasil penelitian ini sesuai dengan penelitian Sunawang. Analisis sampel yang diambil langsung dari pabrik di Jawa Tengah dengan klaster di Pati dan Rembang menunjukkan lebih dari separuh produsen memproduksi garam beriodium dibawah standar. Pada sampel garam briket, hampir semuanya tidak memenuhi syarat kecuali 3 dari 49 perusahaan yang diteliti, atau kurang dari 5\% produsen mempunyai produk garam briket yang memenuhi syarat. Pembuatan garam briket yang dioven telah merusak iodium yang telah difortifikasi sebelumnya. ${ }^{6}$

Pendekatan law enforcement dan social enforcement diperlukan untuk menjamin konsumsi dan ketersediaan garam iodium sesuai SNI. Law enforcement ditujukan kepada produsen/pedagang agar memproduksi atau menjual garam beriodium yang bermutu baik sesuai dengan aturan yang ada. Social enforcement ditujukan kepada konsumen agar selalu memilih garam beriodium yang bermutu baik serta meningkatkan konsumsi makanan sumber iodium. . $^{2,910}$

Tingginya peredaran garam beriodium yang tidak memenuhi syarat di Kabupaten Jepara disebabkan oleh lemahnya law enforcement tentang garam beriodium dari tingkat pusat hingga daerah. Saat ini pendekatan law enforcement di Kabupaten Jepara bertumpu pada Peraturan Daerah (Perda) No. 2 tahun 2009 tentang pengaturan dan pengendalian peredaran garam tidak beriodium. Perda ini terutama ditujukan kepada para pedagang karena semua garam beriodium yang beredar di Jepara berasal dari luar wilayah. Hasil Penelitian menujukkan bahwa Pelaksanaan Perda hanya sebatas sosialisasi di beberapa wilayah saja.

Peraturan Menteri Perindustrian No.88/MIND/PER/10/2014 tentang Peta Panduan (Road Map) Pengembangan Klaster Industri Garam, mengharapkan daerah memiliki perangkat hukum guna mencegah peredaran garam yang tidak sesuai SNI antar wilayah. ${ }^{11}$
Di Jawa Tengah belum terdapat Peraturan Daerah yang dapat digunakan untuk mencegah peredaran garam tersebut keluar daerah/kabupaten. Tata niaga garam antar wilayah hanya dilakukan melalui rapat koordinasi tim penanggulangan GAKI di tingkat propinsi.

Lemahnya law enforcement memberi peluang munculnya moral hazard para produsen. Beberapa produsen garam beriodium membuat kualitas garam dengan berbagai tingkatan. Garam berkualitas baik dijual di daerah produsen sendiri sedangkan garam beriodium berkualitas jelek atau tidak memenuhi syarat dijual ke luar wilayah termasuk Kabupaten Jepara. Bentuk kecurangan lain yang dilakukan oleh produsen adalah menjual garam dengan kualitas yang berbeda dalam satu kemasan untuk mengelabui petugas dan pedagang. Garam dengan berkualitas baik, sebagai contoh garam bata yang memenuhi syarat diletakkan di kemasan bagian atas sedangkan garam bata dengan kualitas rendah diletakkan di bagian bawah. Hal ini dilakukan untuk mengelabui petugas pada saat operasi garam atau ketika pedagang ingin mengecek kandungan iodium secara kualitatif dengan iodine test.

Tingginya peredaran garam beriodium yang tidak memenuhi syarat dipengaruhi pula oleh kinerja tim penanggulangan GAKI yang belum maksimal. Tim penanggulangan GAKI Kabupaten telah ada sejak tahun 1999 dan terdiri dari berbagai instansi pemerintahan. Tim terbagi menjadi tiga bidang yaitu bidang produksi, distribusi dan konsumsi. Bidang produksi bertanggung jawab pada produksi garam beriodium sesuai SNI, bidang distribusi berperan pada distribusi/peredaran garam beriodium sesuai SNI dan bidang konsumsi berperan pada KIE konsumsi garam beriodium oleh masyarakat. Pada bidang produksi, instansi terkait telah mendorong tumbuhnya industri garam beriodium sesuai SNI namun belum didukung koordinasi lintas sektor yang baik. Bidang distribusi, pemantauan garam di pasar sangat terbatas hanya sekali dalam setahun dan terbatas pada pasar besar di tiap kecamatan. Bidang konsumsi, KIE konsumsi garam beriodium dilakukan oleh Dinas Kesehatan saja sehingga terbatas pada kelompok masyarakat tertentu.

Banyaknya produsen yang memproduksi garam beriodium yang tidak memenuhi syarat antara lain karena kurangnya permodalan dan peralatan uji iodisasi, rendahnya kualitas bahan baku, kurangnya pengetahuan mengenai proses iodisasi, kurangnya pengetahuan mengenai dampak GAKI dan belum adanya sanksi yang tegas bagi produsen pelaku pelanggaran. ${ }^{3,12}$

Hasil penelitian di Jepara tidak berbeda dengan kondisi di kabupaten tetangga. Kabupaten Kudus, Pati, Demak dan Rembang telah memiliki Perda tentang garam beriodium, namun konsumsi garam beriodium masih dibawah USI dan peredaran garam beriodium yang tidak sesuai SNI masih tinggi di wilayah 
tersebut. ${ }^{13-17,}$ Kondisi ini sesuai dengan hasil penelitian Sunawang pada tahun 2011. Berdasarkan proporsi penduduk yang telah mengonsumsi garam beriodium, wilayah Jawa Tengah masuk dalam regional 2. Ciri-ciri regional 2 antara lain konsumsi garam beriodium belum pernah mencapai USI serta mempunyai petani garam dan produsen garam beriodium yang memenuhi kebutuhan nasional. Pembiaran produsen garam beriodium skala kecil dan menengah yang tidak melakukan kendali mutu serta masih banyaknya peredaran garam krosok menjadi penyebab regional 2 belum pernah mencapai USI. ${ }^{6}$

Produksi garam krosok yang semakin meningkat dan tingginya peredaran garam beriodium dibawah $30 \mathrm{ppm}$ dari luar wilayah mendorong pemerintah kabupaten untuk menumbuhkan kembali produsen garam beriodium di Jepara guna memenuhi kebutuhan lokal. Terdapat 2 produsen garam beriodium di Jepara yaitu KUB Mutiara Laut dan KSU Mina Barokah. KUB Mutiara Laut telah beroperasi selama 9 tahun dan seluruh produknya dijual keluar wilayah bahkan keluar Pulau Jawa. KSU Mina Barokah beroperasi pada pertengahan tahun 2014 dan pada saat penelitian belum memasarkan produksinya. Pemerintah daerah juga melakukan studi kelayakan pengembangan industri garam beriodium di Kabupaten Jepara. Studi ini bertujuan untuk melihat sejauh mana potensi dan peluang pengembangan industri garam beriodium di Kabupaten Jepara yang dapat ditawarkan pada investor.

\section{Pola Distribusi Garam Beriodium di Kabupaten Jepara}

Distribusi adalah kegiatan penyaluran produk (barang atau jasa) dari produsen ke konsumen. Distribusi barang ikut menentukan ketersediaan barang yang dibutuhkan oleh konsumen. Distribusi garam beriodium dari produsen garam beriodium kepada masyarakat harus merata diseluruh wilayah termasuk daerah terpencil guna memenuhi ketersediaan garam beriodium yang memenuhi syarat. Distribusi garam beriodium dapat dilakukan oleh distributor besar/ agen, toko, supermarket, pasar, dan lain-lain. Pemasaran akhir umumnya melalui pengecer seperti pasar besar, supermarket, toko bahan pangan hingga pengecer kecil seperti warung di daerah perkotaan, pinggiran kota dan pedesaan. $^{18}$

Proses penyaluran produk dari produsen ke konsumen akhir menggunakan berbagai bentuk saluran pemasaran atau pola distribusi, antara lain saluran tingkat nol (zero level channel), saluran tingkat satu (one level channel), saluran tingkat dua (two level channel) dan saluran tingkat tiga (three level channel). Saluran tingkat nol merupakan penyaluran barang dari produsen ke konsumen secara langsung tanpa perantara. Saluran tingkat satu terdapat satu perantara yaitu pengecer diantara produsen dan konsumen. Saluran tingkat dua terdapat dua perantara yaitu agen/pedagang besar dan pengecer, sedangkan saluran tingkat tiga terdapat tiga perantara yaitu agen, pedagang besar dan pengecer. ${ }^{18}$

Hasil penelitian mendapatkan beberapa bentuk saluran pemasaran atau pola distribusi garam yaitu pola distribusi garam dari petani garam ke produsen garam beriodium dan pola distribusi garam beriodium dari produsen ke konsumen. Pola distribusi garam dari petani garam ke produsen garam beriodium dapat melalui 2 bentuk yaitu melalui supplier garam atau tanpa supplier garam. Pola distribusi garam dari produsen ke konsumen menggunakan saluran tingkat satu, dua, dan tiga. Produsen garam beriodium dari Demak dan Pati menggunakan saluran tingkat satu dan dua, sedangkan produsen garam beriodium skala nasional menggunakan saluran tingkat dua dan tiga. Apabila distribusi melalui beberapa tingkatan saluran dan keberadaan pedagang/pengecer tidak di pasar besar, maka garam beriodium tidak dapat terpantau melalui operasi garam oleh tim penanggulangan GAKI. Hal ini sering digunakan oleh para produsen garam beriodium di Demak dan Pati untuk langsung menyalurkan produknya ke pedagang atau pengecer yang ada di tengah-tengah masyarakat (pedagang/pengecer bukan di pasar besar).

Faktor lain yaitu karena pola distribusi garam beriodium tidak melibatkan agen atau distributor khusus garam tetapi langsung didistribusikan ke pedagang besar atau pengecer. Hal ini menyebabkan pedagang atau pengecer berperan besar dalam pengendalian garam beriodium yang tidak memenuhi syarat. Pedagang memiliki peran sebagai penyuluh garam beriodium sesuai SNI kepada konsumen, sehingga perlu melibatkan pedagang secara aktif. Hasil operasi garam oleh tim penanggulangan GAKI juga sebaiknya disosialisasikan kepada pedagang dengan melibatkan kepala pasar setempat serta melakukan KIE tentang GAKI dan garam beriodium kepada para pedagang secara berkala. Pola distribusi garam dari petani hingga konsumen diharapkan tidak ada penjualan garam krosok ke konsumen akan tetapi masih banyak ditemukan penjual garam krosok di pasar maupun pedagang keliling.

Pola distribusi yang berbeda mengakibatkan ketersediaan garam beriodium disetiap wilayah juga berbeda. Tabel 2 menjelaskan terdapat 8-14 merk garam yang berbeda di tiap pasar, dan sebanyak $44,44 \%$ - 83,33 \% dari garam tersebut mengandung iodium dibawah 30 ppm. Persentase terbanyak di Pasar Keling dan Nalumsari (> 80\%), Pasar Lebak dan Welahan (> 70\%), Pasar Mlonggo, Mayong, Batealit dan Bangsri (> 60\%), Pasar Tahunan (60\%), Pasar Ngabul (>50\%), Pasar Donorojo (50\%), dan Kalinyamatan $(<50 \%)$. Garam beriodium yang beredar 
di wilayah Pakis Aji sebanyak 21 merk, 5 merk $(23,81 \%)$ mengandung iodium $\geq 30 \mathrm{ppm}$ dan 16 merk $(76,19 \%)$ mengandung iodium $<30$ ppm. Refina merupakan merk yang sesuai SNI dan dapat ditemukan di semua pasar. Di beberapa pasar terdapat penjual garam krosok curah dan kemasan.

Distribusi garam beriodium dengan kadar 30 ppm atau lebih di tiap wilayah mempengaruhi tingkat konsumsi garam beriodium yang memenuhi syarat. Ketersediaan garam beriodium dengan kadar 30 ppm atau lebih di wilayah endemis GAKI seperti Mayong, Batealit dan Pakis Aji hanya $20-30 \%$. Ketersediaan garam di sekitar wilayah Gunung Muria dan Gunung Clering seperti Nalumsari, Bangsri, Kembang dan Keling < 20\% - 30\%. Monitoring EIU di wilayah Nalumsari, Bangsri, Kembang dan Keling perlu segera dilakukan mengingat letak wilayah geografis dan rendahnya ketersediaan garam beriodium dengan kadar 30 ppm atau lebih.

Garam beriodium yang dijual di pasar modern semuanya mengandung iodium $30 \mathrm{ppm}$ atau lebih yaitu Refina, Dolpin, Daun, Kapal, Garam Indomaret dan Kapal Layar Kokrosono. Merk Kapal dan Dolpin produksi PT. Susanti Megah Surabaya mengandung iodium diatas $80 \mathrm{ppm}$. Tingginya kadar KIO3 menunjukkan kurangnya quality control dalam proses iodiasasi garam. Kandungan KIO3 garam yang berlebih akan meningkatkan resiko terjadinya iodine excess yang menyebabkan Iodine Induced Hyperthyroidism (IIH) atau Iodine Induced Thyrotoxicosis (IIT). Monitoring median EIU secara periodik merupakan kunci utama mencegah terjadinya IIH atau IIT pada masyarakat. ${ }^{19}$

\section{SIMPULAN}

Garam beriodium yang beredar di Kabupaten Jepara berasal dari luar wilayah sebanyak 76 merk, 75\% garam tersebut mengandung iodium dibawah 30 ppm. Tingkat konsumsi garam beriodium rumah tangga di Kabupaten Jepara sebesar 79,89\%. Apabila $75 \%$ garam iodium yang beredar mengandung iodium dibawah 30 ppm, maka diperkirakan konsumsi garam beriodium yang memenuhi syarat (kadar $30 \mathrm{ppm}$ atau lebih) hanya sebesar 19,97\%.

Distribusi garam beriodium dengan kadar $30 \mathrm{ppm}$ atau lebih di tiap wilayah mempengaruhi tingkat konsumsi garam beriodium yang memenuhi syarat. Pola distribusi garam beriodium dari petani garam hingga konsumen melalui berbagai macam cara. Terdapat 814 merk garam yang berbeda disetiap wilayah, $44,44 \%$ - 83,33\% garam tersebut mengandung iodium dibawah $30 \mathrm{ppm}$. Di beberapa wilayah terdapat pedagang garam krosok curah dan kemasan.

\section{DAFTAR PUSTAKA}

1. Tim Penanggulangan GAKY Pusat. Rencana Aksi Nasional Kesinambungan Program Penanggulangan Gangguan Akibat Kurang Iodium. Jakarta : Departemen Kesehatan RI; 2005. p. $1-52$

2. Darmono SS. Penghentian Kapsul Minyak Iodium untuk Program GAKI. Jurnal GAKI Indonesia. 2009; 1\&2 (1\&2):27-31.

3. Tim Penanggulangan GAKI Pusat. Panduan Penegakan Norma Sosial (Sosial Enforcement) : Peningkatan Konsumsi Garam Beriodium. Jakarta : Depkes RI; 2005.p.1-5.

4. Badan Penelitian dan Pengembangan Kesehatan Kementrian Kesehatan RI. Riset Kesehatan Dasar 2013. Jakarta : Kementrian Kesehatan RI; 2013.p. 249-53.

5. Badan Penelitian dan Pengembangan Kesehatan Depkes RI. Riset Kesehatan Dasar 2007. Jakarta : Depkes RI; 2008.p. 60-5.

6. Sunawang. Konsumsi Garam Beriodium di Indonesia, Situasi Saat ini Ditinjau dari Kendali Mutu Oleh Produsen. Jurnal GAKI Indonesia. 2011; 1(9):77 - 100.

7. Sugiyono. Metode Penelitian Kombinasi (Mixed Methods). Bandung : Alfabeta; 2013.p. 283-387.

8. Dinas Kelautan dan Perikanan Kabupaten Jepara. Buku Profil Sektor Kelautan dan Perikanan Kabupaten Jepara 2014. Jepara : Dinas Kelautan dan Perikanan Kabupaten Jepara. 2014.

9. Tim Penanggulangan GAKI Pusat. Rencana Aksi Nasional Kesinambungan Program Penanggulangan Gangguan Akibat Kurang Iodium. Jakarta : Departemen Kesehatan RI; 2005. p. $1-52$

10. Soerharyo S, Margawati A, Setyawan H, Djokomoeljanto. Aspek Sosio-Kultural pada Program Penanggulangan GAKI. Jurnal GAKI Indonesia. 2002; 1(1): $41-8$.

11. Peraturan Menteri Perindustrian Nomor 88/MIND/PER/10/2014. [online]. [diakses 15 Januari 2015] Available from regulasi.kemenperin.go.id/site/peraturan/7/all/20.

12. Susanti S D, Achadi EL. Analisis Penggunaan Garam Beriodium di $15 \mathrm{Kab} / \mathrm{Kota}$ di Indonesia. Jurnal GAKI Indonesia. 2013;2(1):57-82.

13. Peraturan Daerah Kabupaten Pati Nomor 9 tahun 2008. [online]. [diakses 15 Januari 2015] Available from : www.jdih.setjen.kemendagri.go.id/files/KAB P ATI 9 2008.pdf

14. Peraturan Daerah Kabupaten Kudus Nomor 4 tahun 2012. [online]. [diakses 16 Januari 2015] Available from 
www.jdih.setjen.kemendagri.go.id/semua.php?K wil=3319

15. Peraturan Daerah Kabupaten Demak Nomor 11 tahun 2007. [online]. [diakses 16 Januari 2015] Available from www.jdih.setjen.kemendagri.go.id/semua.php?K $\underline{\text { wil }=3321}$

16. Peraturan Daerah Kabupaten Rembang Nomor 12 tahun 2007. [online]. [diakses 16 Januari 2015] Available from

118.97.20.70/repodijital/07/Peraturan

Daerah/2007/perda_rembang_2007_12.pdf

17. Dinas Kesehatan Propinsi Jawa Tengah. Buku Profil Kesehatan Propinsi Jawa Tengah Tahun 2013. Semarang : Dinas Kesehatan Propinsi Jawa Tengah; 2014.

18. Kotler P. Manajemen Pemasaran. Edisi 13 jilid 1. Bob Sabram (alih bahasa). Jakarta : Prentice Hall. 2010; p.106 - 13.

19. Djokomoeljanto. Dampak Iodine Excess Bagi Kesehatan (Iodine Excess in Iodine Deficiency Disorders Prevention Program). Jurnal GAKI Indonesia. 2009; 1\&2 (1\&2):4-14. 